\title{
H-U-E Shaped Slotted Microstrip Antenna for Bandwidth Enhancement
}

\author{
J. Chandrasekhar Rao ${ }^{1}$, K. Pradeep Rajashekar ${ }^{2}$ and G. Prem Kumar ${ }^{3}$ \\ ${ }^{1}$ Assistant Professor, Department of ECE, $K$ L University, A.P, India \\ ${ }^{2,3}$ UG student, Department of ECE, St. Ann's College of Engineering \& Technology, \\ Chirala, A.P India \\ jettychandu@gmail.com
}

\begin{abstract}
An H-U-E shaped slotted microstrip antenna with improved bandwidth is presented in this paper. The antenna resonates in the frequency range of (2.0-6.3) $\mathrm{GHz}$ with the center frequency of $4.2 \mathrm{GHz}$. The proposed antenna provides return loss approximately $-30 \mathrm{~dB}$. The antenna is fed with coaxial feeding yields an impedance bandwidth of 103.6\% and VSWR of less than 1.07. The proposed antenna is simulated using Ansoft's HFSS software. The proposed $\mathrm{H}-\mathrm{U}$-E slotted microstrip antenna is suitable for wireless communications.
\end{abstract}

Keywords: Coaxial feed, Impedance bandwidth, Microstrip slot antenna, Return loss, VSWR

\section{Introduction}

With enormous growth in wireless communications technology from past few years, design of compact, low profile, and wideband antennas for wireless communications is a major challenge for antenna design researchers [1]. Microstrip patch antennas are commonly used in wireless communications like Bluetooth, Wi-Fi, WLAN, WiMax applications owing to their attractive features such as small size and hence conformal nature, easy to feed and design, low fabrication cost, robust nature, light in weight, and easily integrate with monolithic microwave integrated circuits (MMIC) [2]. However, standard microstrip patch antennas cannot satisfy the bandwidth requirements for most wireless communication systems because of their narrow bandwidth. This inherent drawback poses design challenge for the microstrip antenna designer to meet the requirements of wireless communications [3, 4]. Over the years various well-known designs have been investigated to improve the bandwidth of the microstrip antennas including the use of thicker substrates [5], use of different shapes of patch $[6,7,8]$, use of low dielectric substrate, use of various impedance matching and feeding techniques like microstrip line or coaxial feeding [9], use of stacked microstrip patches [10] and parasitically coupled or gap-coupled patches [11], and the use of shorting pins [12].

Several Slot antennas with different shapes are proposed in the literature to enhance the bandwidth of the antenna. Microstrip square shaped ring slot antenna filled by an $\mathrm{H}$-shape slot for Ultra Wideband (UWB) applications is presented in [13]. This structure is fed by a single microstrip line with a fork like-tuning stub giving bandwidth of 19\%. In [14], authors proposed E-shaped slot antenna which is fed by CPW and microstrip line providing bandwidth of nearly $140 \%$. Broadband asymmetric u-slot patch antenna with narrow probe to enhance bandwidth for wideband communications is reported in [15]. This design gives an impedance bandwidth of $30 \%$. Slot antenna with other shapes are investigated to enhance the bandwidth of microstrip antennas for broadband communications such as open L-slot [16], wide slot [17], T-slot [18], cross-shaped slot antennas [19].

In this paper, a novel antenna design is presented which is having three different slots namely $\mathrm{H}, \mathrm{U}$, and $\mathrm{E}$ with equally spaced on the single patch for satisfying the bandwidth requirements of wideband communications. Various types of slots such as 
H-slot, U-slot, and E-slot are previously investigated to enhance the bandwidth and proved to give impedance bandwidths of $19 \%, 30 \%$, and $140 \%$ respectively $[13,15$, 14]. However, the combination of these slots together on a single patch led to enormous broadening of the bandwidth. The proposed H-U-E slotted antenna resonates in the frequency range of (2.0-6.3) $\mathrm{GHz}$ with the center frequency of $4.2 \mathrm{GHz}$. The proposed antenna fed by coaxial feeding provides return loss approximately $-30 \mathrm{~dB}$. An impedance bandwidth of $103.6 \%$ and VSWR $\leq 1.07$ is obtained from the proposed antenna. Ansoft's HFSS software is used to design and analyze the proposed antenna.

\section{Proposed Slot Antenna Design}

The proposed antenna is designed for wireless communications such as Bluetooth, wireless LAN (WLAN), and Wi-Fi. The proposed antenna is resonating in the frequency range from $2.0 \mathrm{GHz}-6.3 \mathrm{GHz}$ with a center frequency of $4.2 \mathrm{GHz}$. Three individual slots namely $\mathrm{H}, \mathrm{U}$, and $\mathrm{E}$ are provided on the patch to enhance the bandwidth of the antenna which is useful for wireless communications. The geometry of the designed antenna is shown in Figure 1.

Table 1. Dimensions of the Proposed Slot Antenna

\begin{tabular}{|l|l|}
\hline Parameter \& Symbol & Dimensions (mm) \\
\hline Patch length (L) & 50 \\
Patch width (W) & 50 \\
Slot length (l) & 30 \\
Slot width (w) & 10 \\
Slot thickness (t) & 2 \\
Slot distance (d) & 5 \\
Inner conductor radius (r) & 2 \\
Outer conductor radius (R) & 3.7 \\
\hline
\end{tabular}

In the proposed antenna all the three slots are used and equally spaced on the patch for simplicity. The substrate FR4 is used with dimensions $50 \times 50 \times 5(\mathrm{~mm})$ having the dielectric constant value of $\varepsilon_{\mathrm{r}}=4.4$. The antenna is provided with coaxial feed with suitable inner and outer conductor diameters. The feed position is centered at right-top corner of the patch with $5 \mathrm{~mm}$ spacing from either side. The dimensions of the patch and the slots are shown in the Table 1. It is to be noted that the lengths, widths, thicknesses of all the three slots are equal as shown in the Figure 1.

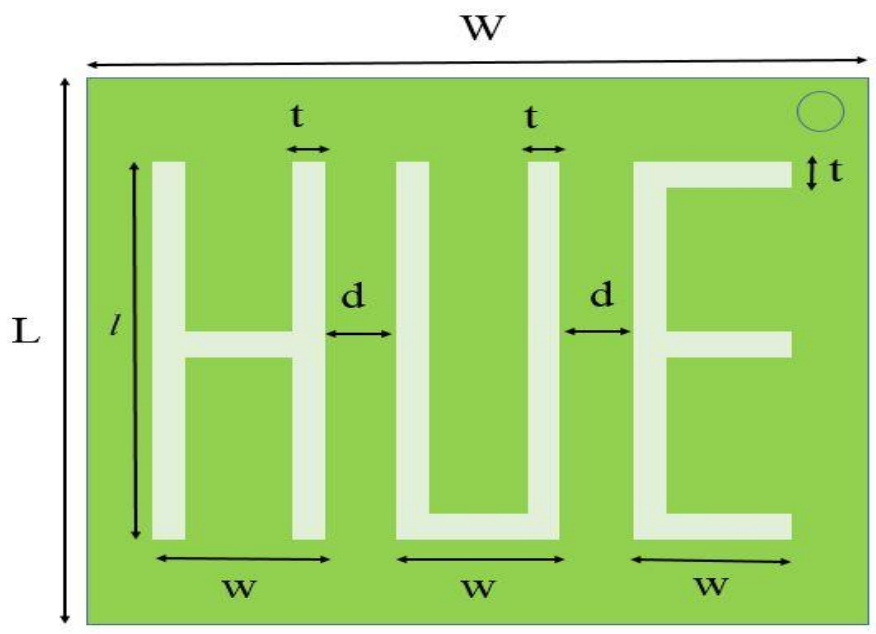

Figure 1. Geometry of H-U-E Slotted Antenna (Top view) 


\section{Results and Discussions}

The HFSS design of proposed H-U-E slotted microstrip antenna with above dimensions is shown in Figure 2. The microstrip antenna parameters like return loss, Voltage Standing Wave Ratio (VSWR), radiation patterns, E-field and $\mathrm{H}$-field distributions are analyzed using the HFSS software. The following sub-sections discussed the above mentioned antenna parameters.

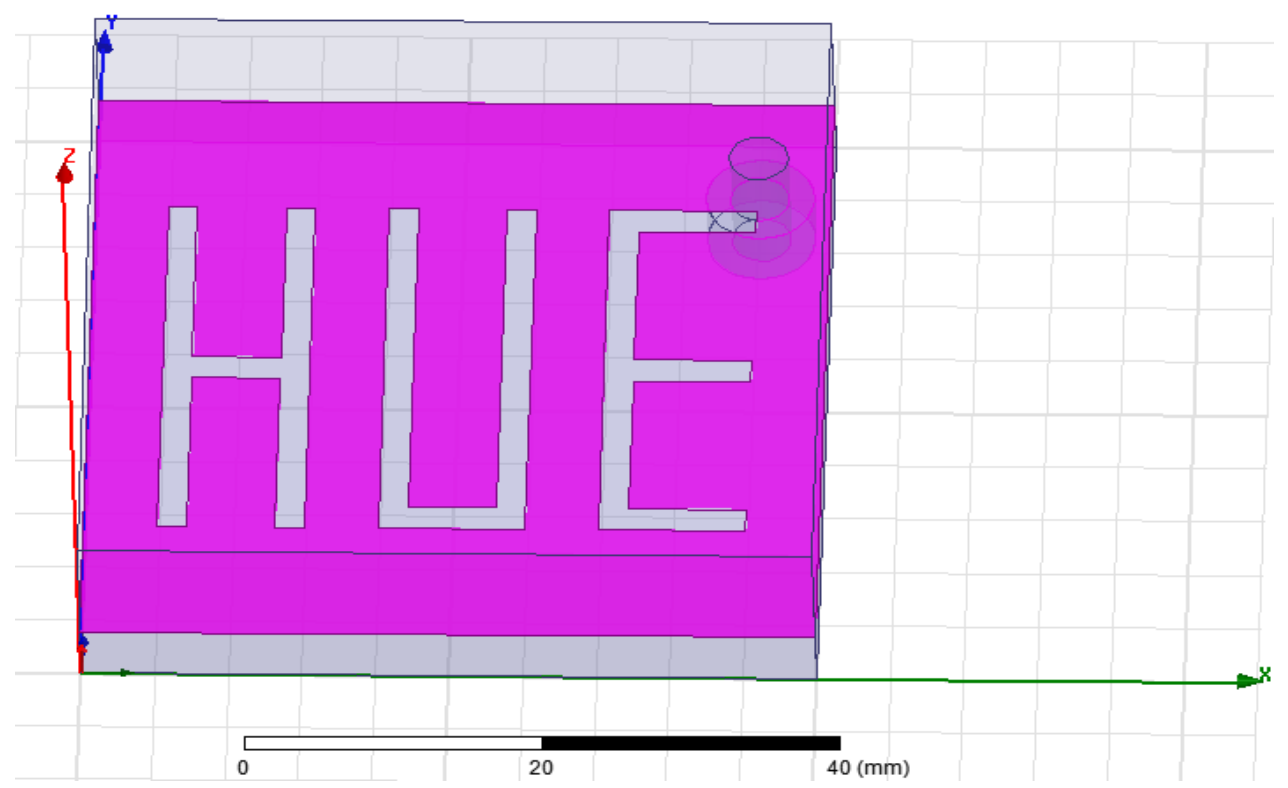

Figure 2. HFSS Design for the HUE Slotted Antenna

\subsection{Return Loss}

Return loss is the ratio of power reflected to the power delivered expressed in negative logarithmic dB. The return loss should be as low as possible (tends to negative value) for maximum power delivery in microstrip antennas. The proposed antenna is resonating at the center frequency of $4.2 \mathrm{GHz}$ giving acceptable return loss of $-28 \mathrm{~dB}$. The return loss plot of the designed antenna is shown in the Figure 3.

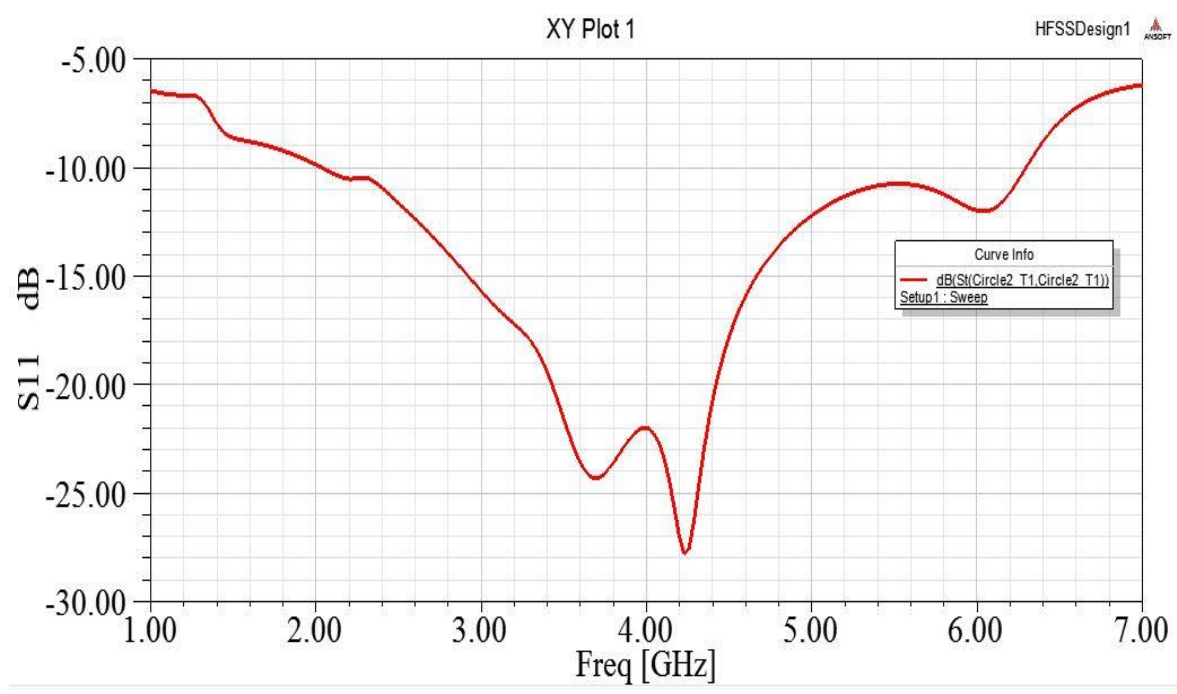

Figure 3. Return Loss Plot of the Proposed Antenna 
The impedance bandwidth can be measured from the return loss plot of the antenna. Impedance bandwidth of $103.6 \%$ is obtained from the proposed H-U-E shaped slot antenna which is very better than the individual bandwidth of $\mathrm{H}, \mathrm{U}$, and $\mathrm{E}$ slot antennas. The bandwidth is measured between the frequencies from $2.0 \mathrm{GHz}$ to $6.3 \mathrm{GHz}$ which is $103.6 \%$ as observed from Figure 3.

\subsection{VSWR}

The VSWR is a measure of the impedance mismatch between the antenna and the transmission line connected to it. Higher the VSWR, greater is the mismatch between antenna and feed line. For wireless communications VSWR of unity is recommended. The plot between VSWR and frequency of the proposed antenna is shown in Figure 4. The voltage standing wave ratio for proposed antenna is observed to be $\leq 1.07$ which is close to unity.

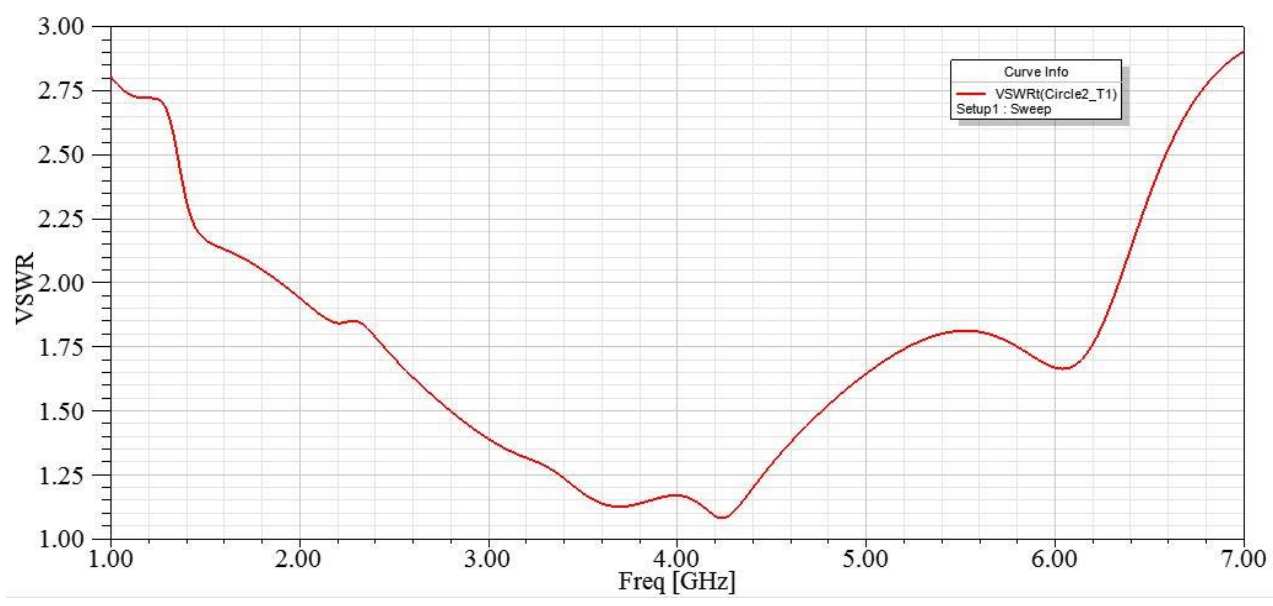

Figure 4. VSWR Plot of the Proposed Antenna

\subsection{Radiation Pattern}

Radiation pattern is the graphical representation and it shows the variation of power radiated by the antenna as a function of the direction away from the antenna. The radiation characteristics of the designed antenna is represented by the $2 \mathrm{D}$ radiation pattern at $\mathrm{Phi}=0$ deg, Phi=90 deg for all theta as observed from the Figure 5.

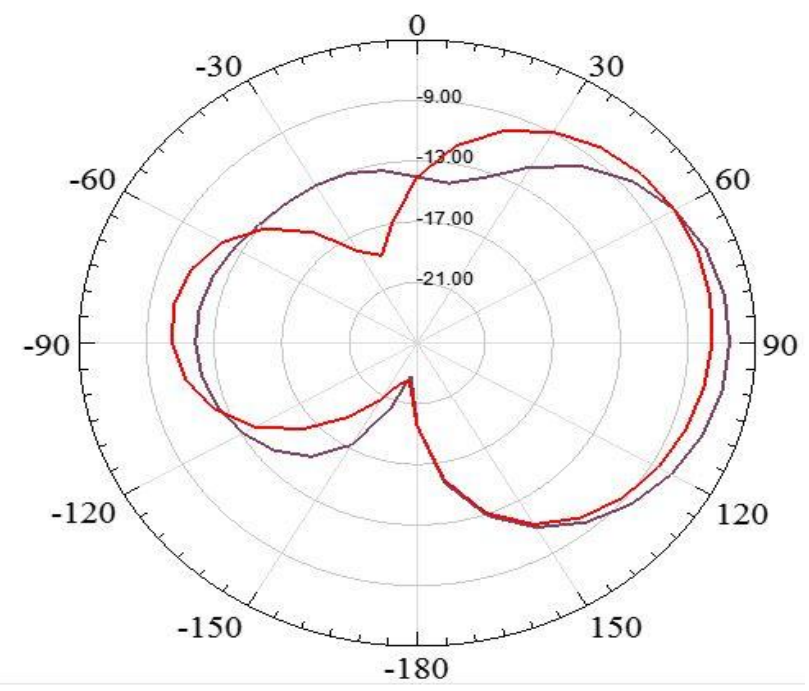

Figure 5. Radiation Pattern of the Proposed Antenna 


\subsection{E-field Distribution}

The electric field (E-field) plot for the proposed antenna is shown in the Figure 6. The electric field distribution on the surface the patch describes the direction of electric field lines at each point in the field. Usually, the path of the electric field lines is from positive to negative charged points.

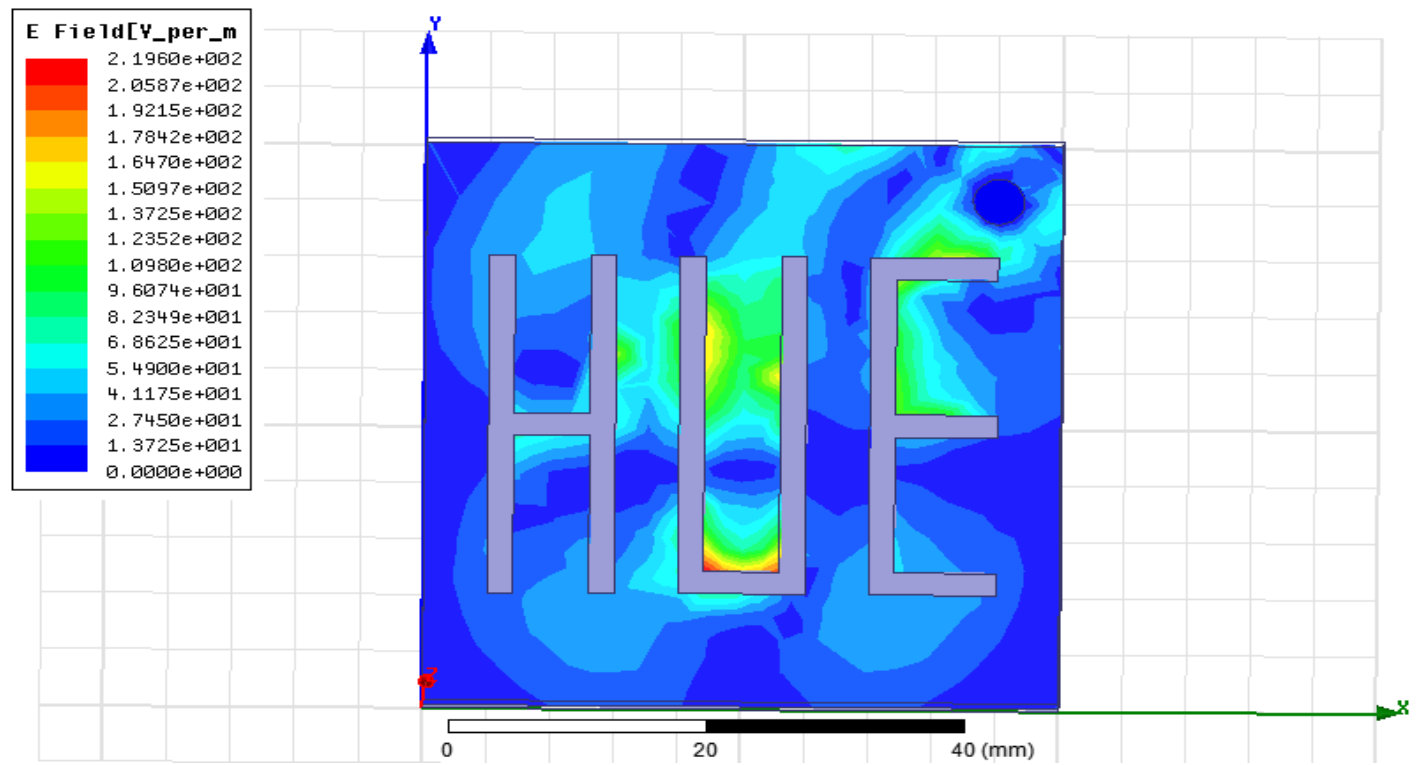

Figure 6. E-field Pattern of the Proposed Antenna

\subsection{H-field Distribution}

The magnetic field (H-field) distribution on the surface of the patch determines the direction of magnetic field vector. The $\mathrm{H}$-field vector always assumes perpendicular direction to that of the electric field. The H-field plot for the proposed antenna is shown in the Figure 7.

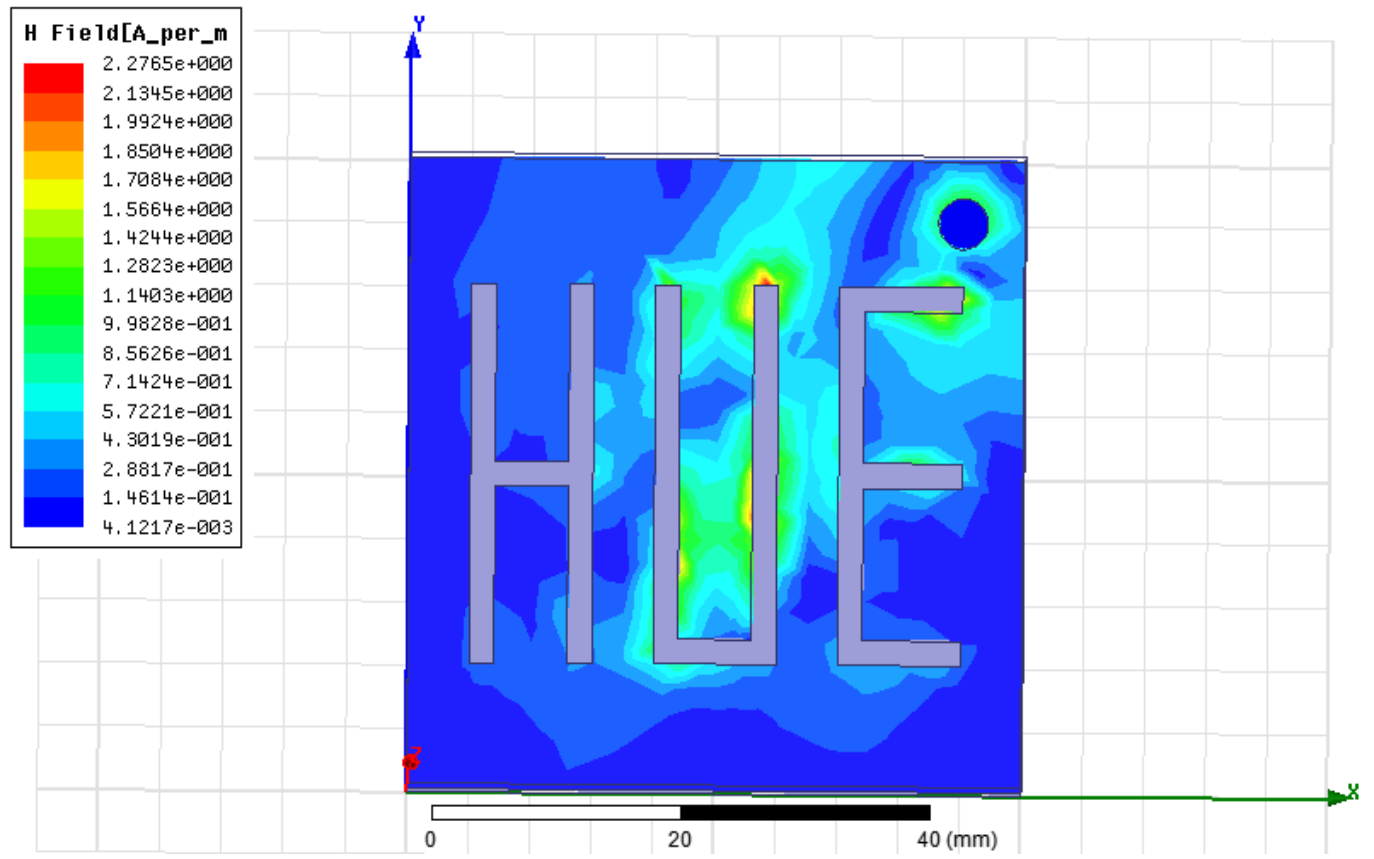

Figure 7. H-field Pattern of the Proposed Antenna 


\section{Conclusion}

A novel slot antenna deign namely H-U-E slotted microstrip antenna to improve the bandwidth for wireless communications is presented in this paper. The antenna resonates in the frequency range of $(2.0-6.3) \mathrm{GHz}$ with the center frequency of $4.2 \mathrm{GHz}$. Return loss approximately $-30 \mathrm{~dB}$ with impedance bandwidth of $103.6 \%$ is obtained from the designed antenna. The antenna is fed with coaxial feeding yields acceptable VSWR of less than 1.07. The proposed antenna is simulated using Ansoft's HFSS software. The proposed H-U-E slotted microstrip antenna is suitable for Bluetooth, Wi-Fi, WLAN, WiMax wireless communications.

\section{Acknowledgement}

The authors would like to thank to the management of St. Ann's College of Engineering and Technology and the Department of Electronics and Communication Engineering for their continuous support and encouragement during this work.

\section{References}

[1] S. L. S. Yang, A. A. Kishk and K. F. Lee, "Frequency reconfigurable U-slot microstrip patch antenna", IEEE Antennas and Wireless Propagation Letters, vol. 7, (2008), pp. 127-129.

[2] K.-L. Wong, "Compact and Broadband Microstrip Antennas", Wiley and Sons, Inc., New York, vol. 1, (2002), pp. 12-15.

[3] Y. P. Zhang and J. J. Wang, "Theory and analysis of differentially-driven microstrip antennas", IEEE Transactions on Antennas and Propagation, vol. 54, (2006), pp. 1092-1099.

[4] D. M. Pozar and D. H. Schaubert, "Microstrip Antennas: The Analysis and Design of Microstrip Antennas and Arrays", IEEE Press, New York, (1995).

[5] J. R. James and P. S. Hall, "Handbook of Microstrip Antennas", Peter Peregronic Ltd., London, (1989).

[6] Y. Ge, K. P. Esselle and T. S. Bird, "E-Shaped patch antennas for high-speed wireless networks", IEEE Transaction on Antennas and Propagation, vol. 52, (2004) December 12, pp. 3213-9.

[7] A. Ali, L. Neyestanak, et al., "W-shaped enhanced bandwidth patch antenna for wireless communication", Wireless Pers. Communication, vol. 43, (2007), pp. 1257-1265.

[8] M. Abbaspour and H. R. Hassani, "Wideband star-shaped microstrip patch antenna", Progress in Electromagnetics Research Letters, vol. 1, (2008), pp. 61-68.

[9] M. M. Matin, B. S. Sharif and C. C. Tsimenidis, "Probe fed stacked patch antenna for wideband applications", IEEE Transactions on Antennas and Propagation, vol. 55, no. 8, (2007), pp. 385-2388.

[10] J. A. Ansari and R. B. Ram, "Broadband stacked U-slot microstrip patch antenna", Progress In Electromagnetics Research Letters, vol. 4, (2008), pp. 17-24.

[11] J. A. Ansari, R. B. Ram and P. Singh, "Analysis of a gap-coupled stacked annular ring microstrip antenna", Progress In Electromagnetic Research B, vol. 4, (2008), pp. 147-158.

[12] J. A. Ansari, P. Singh, N. P. Yadav and B. R. Vishvakarma, "Analysis of shorting pin loaded half disk patch antenna for wideband operation", Progress In Electromagnetic Research C, vol. 6, (2009), pp. 179-192.

[13] S. Sadat, M. Houshmand and M. Roshandel, "Design of a microstrip square-ring slot antenna filled by an Hshape slot for UWB", Progress in Electromagnetic Research, vol. 70, (2007), pp. 191-198.

[14] A. Dastranj and H. Abiri, "Bandwidth enhancement of printed E-shaped slot antennas fed by CPW and microstrip line", IEEE Transactions on Antennas and Propagation, vol. 58, no. 4, (2010) April.

[15] G. F. Khodaei, "A practical miniaturized u-slot patch antenna with enhanced bandwidth", Progress In Electromagnetic Research B, vol. 3, (2008), pp. 47-62.

[16] W. S. Chen and K. Y. Ku, "Broadband design of non-symmetric ground $\lambda / 4$ open slot antenna with small size", Microwave Journal, vol. 50, (2007) pp. 110-121.

[17] A. Dastranj and M. Biguesh, "Broadband coplanar waveguide-fed wide-slot antenna", Progress In Electromagnetics Research C, vol. 15, (2010), pp. 89-101.

[18] J. J. Jiao, G. Zhao, F. S. Zhang, H.-W. Yuan and Y.-C. Jiao, "A broadband CPW-fed T-shape slot antenna", Progress In Electromagnetics Research, vol. 76, (2007), pp. 237-242.

[19] Y. W. Jang, "Broadband cross-shaped microstrip-fed slot antenna," Electronic Letters, vol. 36, no. 25, (2000) December, pp. 2056-2057. 


\section{Authors}

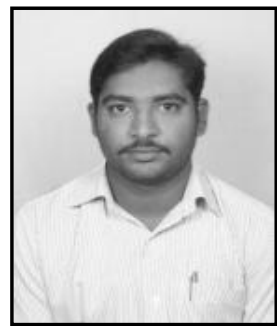

J. Chandrasekhar Rao, was born in India, A.P in 1985. He received his B. Tech, M.Tech degrees in ECE. He is currently working as Assistant professor in ECE department of K L University, Vijayawada. $\mathrm{He}$ has 4 national conference papers, and 6 international journal publications. His research interests include microstrip antennas, image processing and microprocessors.

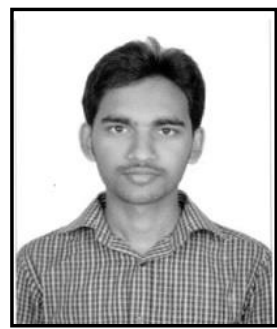

K. Pradeep Rajashekar was born in 1993 at Guntur District, Andhra Pradesh state, India. He Graduated in Electronics and Communication Engineering from St.Ann's college of Engineering \& Technology College, affiliated to JNTU Kakinada University, Chirala.

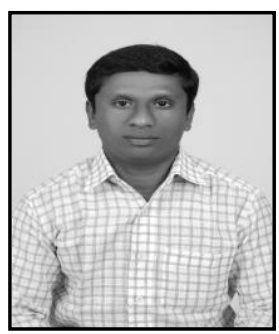

G. Prem Kumar was born in 1993 at Prakasam District, Andhra Pradesh state, India. He Graduated in Electronics and Communication Engineering from St. Ann's college of Engineering \& Technology College, affiliated to JNTU Kakinada University, Chirala. 
International Journal of Future Generation Communication and Networking Vol.7, No.4 (2014) 